О. Ю. Оношко

Байкальский государственный университет, г. Иркутск, Российская Федераиия

А. П. Кряжева

Байкальский государственный университет, г. Иркутск, Российская Федерация

И. Д. Шигаева

Байкальский государственный университет, г. Иркутск, Российская Федерация

\title{
БАНКОВСКАЯ СИСТЕМА РОССИЙСКОЙ ФЕДЕРАЦИИ: СОВРЕМЕННОЕ СОСТОЯНИЕ И ПЕРСПЕКТИВЫ РАЗВИТИЯ
}

\begin{abstract}
АНнотАЦия. В современных условиях нестабильности финансовых рынков и возрастающей неопределенности в экономической сфере требования к надежности российской банковской системы значительно возрастают. На развитие банковской системы Российской Федерации оказывают влияние мировые тенденции, характерные для современного банковского дела. В настоящее время они настолько значительны, что многие европейские специалисты называют происходящее банковской революцией. Среди наиболее важных тенденций называют возрастающую конкуренцию с небанковскими кредитными учреждениями, дерегулирование, технологическую и техническую революцию, интернационализацию и глобализацию. В статье представлен анализ современной банковской системы России, исследуется динамика действующих коммерческих банков и небанковских кредитных организаций Российской Федерации в разрезе федеральных округов за кризисные и посткризисный периоды. Рассмотрено влияние на эти процессы ключевой ставки и ресурсной базы кредитных организаций, систематизируются проблемы, характерные для исследуемого периода и приводятся меры, необходимые к принятию на российском финансовом рынке для преодоления современных трудностей и дальнейшего эффективного развития. В основу анализа положены статистические данные Банка России и Агентства по страхованию вкладов.

КЛЮчЕВЫЕ СЛОВА. Банковская система Российской Федерации; показатели банковской деятельности; финансовый рынок; ключевая ставка; ресурсная база коммерческих банков; активы банковского сектора.

ИНФОРМАЦИЯ О СТАТЬЕ. Дата поступления 1 июня 2016 г.; дата принятия к печати 28 июня 2016 г.; дата онлайн-размещения 30 сентября 2016 г.
\end{abstract}

O. Yu. Onoshko Baikal State University, Irkutsk, Russian Federation

A. P. Kryazheva Baikal State University, Irkutsk, Russian Federation

L. D. Shigayeva Baikal State University, Irkutsk, Russian Federation

\section{BANKING SYSTEM OF THE RUSSIAN FEDERATION: CURRENT SITUATION AND DEVELOPMENT PROSPECTS}

ABSTRACT. In modern terms of financial market instability and growing uncertainty in the economic sphere, the requirements for reliability of the Russian banking system

\section{Baikal Research Journal}


are increasing significantly. Global tendencies characteristic for present-day banking have an impact on the banking system of the Russian Federation. Currently, they are so significant that many European experts call the current developments a revolution of banks. Among the most important trends referred to is an increasing competition with non-bank credit institutions, deregulation, technological and technical revolution, internationalization and globalization. The article presents an analysis of Russia's modern banking system, investigates the dynamics of existing commercial banks and non-bank credit institutions of the Russian Federation in terms of the federal districts during crisis and post-crisis periods. It considers the influence of the key interest rate and the resource base of credit organizations on these processes, systemizes the problems characteristic for the period studied and brings forth the measures that are necessary to adopt on the Russian financial market for overcoming the present-day difficulties and for further effective development. As a basis of the analysis it uses the statistical data of the Bank of Russia and Deposit Insurance Agency.

KEYWORDS. Banking system of the Russian Federation; financial performance indicators; financial market; key interest rate; resource base of commercial banks; banking sector assets.

ARTICLE INFO. Received June 1, 2016; accepted June 28, 2016; available online September $30,2016$.

Глобальные тенденции в экономике последних лет доказали тесную взаимосвязь процессов развития реального и финансового секторов. Одной из причин разрастания кризиса в мировой экономике явилась дестабилизация финансового сектора в целом. В настоящее время эксперты стали говорить о возможном преодолении острой фазы кризиса, однако, признавая наличие первых признаков образования рецессии (в том числе и в России). Так, председатель Центрального банка РФ (ЦБ РФ) Э. Набиулина считает, что по основным показателям, характеризующим банковскую систему, ее «можно назвать устойчивой, она находится в безопасной зоне» ${ }^{1}$. Председатель комитета Госдумы РФ по экономической политике, президент ассоциации «Россия» А. Аксаков также считает, что российская банковская система уже прошла нижние значения в своем развитии [1]. В этой связи исследование направлений развития банковской системы как основного звена кредитно-финансовой системы страны является актуальным, поскольку стабильность и эффективность банковского сектора - это основное условие стабильного развития российской экономики.

Количественно характеризуя тенденции в развитии банковской системы России, нужно констатировать общее сокращение числа банковских и небанковских кредитных организаций в ее составе. В настоящее время ЦБ РФ осуществляет «чистку» (санацию) банковской системы, сокращая численность действующих кредитных организаций и отзывая лицензии у тех банков, которые не отвечают требованиям регулятора [2]. В январе - октябре 2015 г. ЦБ РФ отозвал лицензии у 64 банков. Как показывает практика (табл. 1), наиболее часто встречаются следующие причины отзыва лицензии:

- несоблюдение положений федерального законодательства, касающегося противодействия отмыванию (легализации) доходов, полученных преступным путем, и финансирования терроризма;

- утрата значительной части капитала;

- проведение разного рода сомнительных операций;

- высокорискованная кредитная политика, отсутствие резервов на возможные потери соразмерно принятым рискам;

- финансовая неустойчивость кредитной организации;

${ }^{1}$ Взгляд: деловая газета. URL : http://vz.ru/news/2015/8/10/760442.h-tml.

\section{Baikal Research Journal}


- представление в контролирующий орган недостоверной отчетности, невыполнение предписаний надзорного органа;

- нарушение норм банковского законодательства и др. [3].

Динамика количества действующих коммерческих банков и небанковских кредитных организаџий Российской Федераџии в разрезе федеральных округов РФ за 2008-2015 22.

\begin{tabular}{|l|r|r|r|r|r|r|r|r|r|}
\hline Федеральный округ & 2008 & 2009 & 2010 & 2011 & 2012 & 2013 & 2014 & 2015 & $\begin{array}{c}\text { Прирост / } \\
\text { уменьшение }\end{array}$ \\
\hline Крымский & - & - & - & - & - & - & - & 2 & 2 \\
\hline Уральский & 63 & 58 & 54 & 51 & 45 & 44 & 42 & 35 & -28 \\
\hline Центральный & 632 & 621 & 598 & 585 & 572 & 564 & 547 & 504 & -128 \\
\hline Сибирский & 68 & 68 & 62 & 56 & 54 & 53 & 51 & 44 & -24 \\
\hline Приволжский & 134 & 131 & 125 & 118 & 111 & 106 & 102 & 92 & -42 \\
\hline Дальневосточный & 40 & 36 & 31 & 27 & 26 & 23 & 22 & 22 & -18 \\
\hline Южный & 118 & 115 & 113 & 47 & 45 & 46 & 46 & 43 & -75 \\
\hline
\end{tabular}

Составлено по данным Центрального банка PФ. URL : http://www.cbr.ru.

Анализируя представленные данные (см. табл. 1), можно сделать вывод, что основное количество коммерческих банков и небанковских кредитных организаций сосредоточено в центральной части России, на долю обширных земель за Уралом приходится менее 10 \% кредитных учреждений. Их сокращение за исследуемый период идет более быстрыми темпами, чем в целом по банковской системе России (на $8,71 \%$ ). Если по Российской Федерации в 2015 г. банков в среднем стало на $26,58 \%$ меньше, то в Сибирском федеральном округе - на 35,9 \% . Заметим, что доля кредитных учреждений Сибирского федерального округа стабильно составляет в банковской системе РФ 6 \% . В целом, за исследуемый период банковская система РФ сократилась на 302 кредитных организаций [4].

На 1 февраля 2016 г. в России действует 676 коммерческих банков. По прогнозам аналитиков, в ближайшем будущем их должно остаться 300. В 2014 г. крупные российские банки начали сокращать собственные филиалы (табл. 2). В 2015 г. эта тенденция ускорилась и продолжается в настоящее время. Очищение банковской системы закончится к 2018 г. Это повысит доверие ЦБ РФ к кредитным организациям, следовательно, следует ожидать более смелого рефинансирования банков для кредитования различных проектов.

Ресурсная база коммерческих банков из-за сокращения инвестиций и потребительских расходов в 2015 г. развивалась достаточно хорошо. В отчетном году вклады физических лиц существенно увеличились [5]. Ключевыми факторами роста стали повышенная сберегательная активность населения, капитализация высоких процентных ставок и валютная переоценка (увеличение курсов иностранных валют по отношению к рублю). В большей степени важным стабилизирующим фактором стало повышение в конце 2014 г. максимального размера страхового возмещения с 700 тыс. до 1,4 млн р. [6]. В 2015 г. объем вкладов населения в банках увеличился на 4666,4 млрд р. (в 2014 г. - на 1595,2 млрд р.) до 23219,1 млрд р. В относительном выражении рост показал 25,2 \% (в 2014 г. $9,4 \%)^{2}$. Объем вкладов индивидуальных предпринимателей на 31 декабря 2015 г. составил 266,1 млрд р. (1, $2 \%$ общей суммы вкладов физических лиц), увеличившись с начала года на $16,9 \%$ (рис. 1 ).

2 Годовой отчет государственной корпорации «Агентство по страхованию вкладов» за 2015 год. URL : https://www.asv.org.ru.

\section{Baikal Research Journal}

электронный научный журнал Байкальского государственного университета 
Таблица 2

Основные показатели развития банковской системы Российской Федерации в 2010-2015 г2., млрд р.

\begin{tabular}{|c|c|c|c|c|c|c|}
\hline Составляющие & 2010 & 2011 & 2012 & 2013 & 2014 & 2015 \\
\hline Активы (пассивы) & 33803 & 41628 & 49510 & 57423 & 77653 & 83000 \\
\hline Прирост за 12 мес., \% & 14,88 & 23,14 & 18,93 & 15,98 & 35,20 & 6,90 \\
\hline $\begin{array}{l}\text { Кредиты экономике (нефинансовым } \\
\text { организациям и физическим лицам) }\end{array}$ & 18515 & 23952 & 28654 & 33635 & 40866 & 43985 \\
\hline Прирост за 12 мес., \% & 12,5 & 29,4 & 19,6 & 21,5 & 25,9 & 7,6 \\
\hline Кредиты нефинансовым организациям & 14530 & 18401 & 20917 & 23678 & 29536 & 33301 \\
\hline Прирост за 12 мес., \% & 12,8 & 26,6 & 13,7 & 13,2 & 31,3 & 12,7 \\
\hline Кредиты физическим лицам & 4085 & 5551 & 7737 & 9957 & 11330 & 10684 \\
\hline Прирост за 12 мес., \% & 14,3 & 35,9 & 39,4 & 28,7 & 13,8 & $-5,7$ \\
\hline $\begin{array}{l}\text { Кредиты финансовым организаци- } \\
\text { ям-резидентам (кроме кредитных } \\
\text { организаций) }\end{array}$ & - & 609,5 & 828,6 & - & 1306,0 & 1659,0 \\
\hline Прирост за 12 мес., \% & - & - & 36,0 & - & 10,8 & 27,0 \\
\hline Прибыль текущего года & 581 & 848,2 & 1013 & 994 & 589 & 192 \\
\hline Вклады физических лиц & 9818 & 11871 & 14251 & 16953 & 18553 & 23219 \\
\hline Прирост за 12 мес., \% & 63,6 & 20,9 & 20,0 & 19,0 & 9,4 & 25,2 \\
\hline $\begin{array}{l}\text { Депозиты и средства организаций на } \\
\text { счетах (кроме кредитных организаций) }\end{array}$ & 11126,9 & 13995,7 & 15648,0 & 17947,0 & 23419,0 & 27064,0 \\
\hline Прирост за 12 мес., \% & 16,42 & 25,80 & 11,80 & 14,70 & 38,60 & 15,60 \\
\hline Кредиты, полученные от Банка России & 1706,8 & 1212,1 & 2690,9 & 3808,8 & 9287,0 & 5363,0 \\
\hline Доля в пассивах & 5,0 & 2,9 & 5,4 & 7,7 & 12,0 & 6,5 \\
\hline
\end{tabular}

Составлено по данным Центрального банка РФ. URL : http://www.cbr.ru.

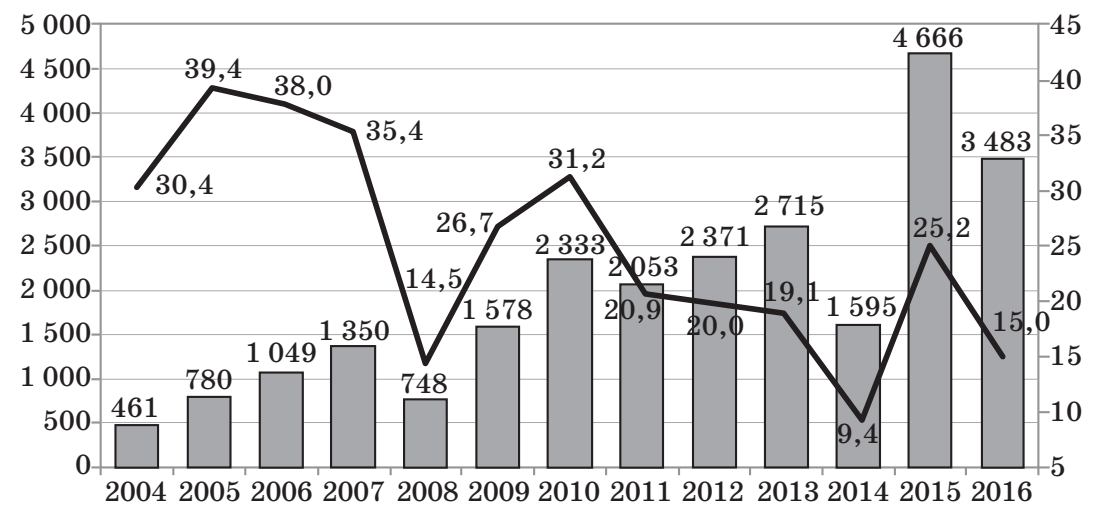

$\square$ Прирост, млрд р. $\quad \longrightarrow$ Прирост, \%

Рис. 1. Приросты вкладов населения в 2004-2016 г2.

В отчетный период наиболее активно росли средние и крупные вклады. По итогам года вклады от 700 тыс. до 1 млн р. увеличили свою долю с 8 до 8,5 \%, а вклады свыше 1 млн р. - с 42,8 до 52,4 \% общей суммы депозитов. Доля вкладов размером от 100 тыс. до 700 тыс. р. уменьшилась с 37,4 до 29,2 \% (рис. 2).

Доля депозитов в иностранной валюте за год выросла с 26,1 до 29,4%, при этом основной рост наблюдался в III кв. (на 3,3 процентных пункта). Доля 30 крупнейших по объему вкладов банков в 2015 г. увеличилась с 79,2 до 81,7 \%, в том чис-

\section{Baikal Research Journal}

электронный научный журнал Байкальского государственного университета 
ле доля Сбербанка России выросла на 1 процентный пункт (с 44,9 до 45,9 \% ${ }^{3}$ ). Что касается средств ЦБ РФ в кредитных организациях, то они сократились в 2 раза (с 12 до 6,5 \% ). Таким образом, средства клиентов заместили средства ЦБ РФ.

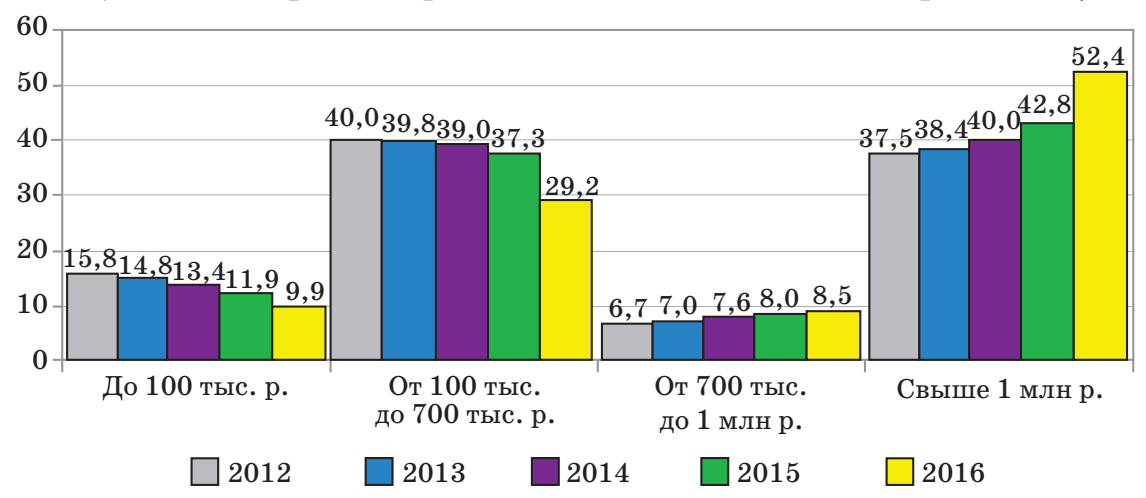

Рис. 2. Структура депозитов в зависимости от размера вкладов в 2012-2016 г2. (на 1 января), \%

Активы банковского сектора за 2015 г. выросли на 6,9 \% против 35 \% в 2014 г. Это самый плохой результат за постсоветскую историю России. Сама структура активов претерпела мало изменений. Увеличилась доля ценных бумаг за счет других видов ликвидных активов - следствие роста доходности по ценным бумагам, а также превращения операций РЕПО в полноценный инструмент рефинансирования [5]. В 2015 г. прибыль банковского сектора составила 192 млрд р. - в 2,5 раза меньше, чем в 2014 г. и в 5 раз меньше, чем в 2013 г. (рис. 3). Причем 300 млрд р. заработал ПАО «Сбербанк России» и 108 млрд р. составили убытки кредитных организаций. К основным причинам можно отнести:

Процентные ножницы (в конце 2014 г. ЦБ РФ была резко повышена ставка рефинансирование, приведшая к росту процентов по вкладам, которая в 2015 г. начала снижаться, а за ней стали уменьшаться и проценты по кредиту).

Резкий рост резервов, связанный с увеличением проблемных кредитов. Резервы на возможные потери по ссудам на 1 января 2016 г. составили 1352 млрд р., т. е. они выросли более, чем на 30 \% в 2015 г., чему способствовали требования ЦБ РФ. В 2016 г. ожидается прибыль российских банков в размере 400 млрд р. ${ }^{4}$

Говоря о тенденциях развития банковской системы, нельзя обойти вопрос о ключевой ставке - процентной ставке по основным операциям ЦБ РФ по регулированию ликвидности банковского сектора, которая в настоящее время составляет $11 \%$ (т. е. это ставка ЦБ РФ, по которой он предоставляет кредиты коммерческим банкам и принимает от них депозиты сроком на одну неделю). С 16 июня по 2 августа 2015 г. ключевая процентная ставка составила 11,50 \% , а с 3 августа 2015 г. по сегодня $-11 \%$.

Средняя ставка по рублевым депозитам сейчас достаточно активно меняется вслед за снижением ключевой ставки и составляет около $10-11$ \% годовых ${ }^{5}$. Ставки по кредитам варьируются по коммерческим банкам очень широко.

${ }^{3}$ Годовой отчет государственной корпорации «Агентство по страхованию вкладов» за 2015 год. URL : https://www.asv.org.ru.

${ }^{4}$ URL : http://riarating.ru/banks_study/20151225/630005336. html.

${ }^{5}$ URL : http://vz.ru/news/2015/8/10/760442.h-tml.

\section{Baikal Research Journal}




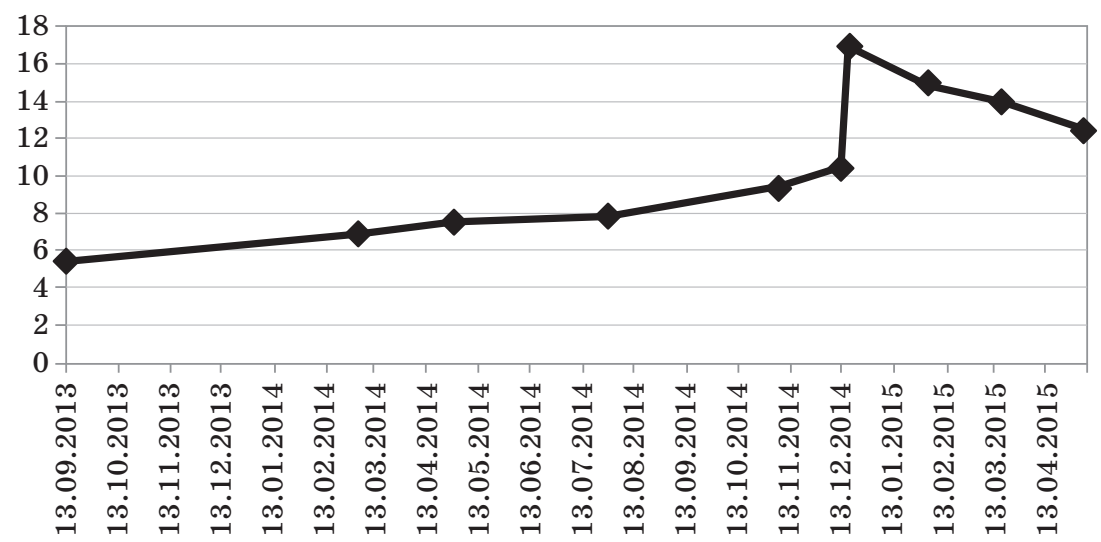

Рис. З. Диналика ключевой ставки Центрального банка РФ за 2013-2015 г2.

Собственный капитал банковской системы РФ в 2015 г. вырос на 13,6 \% или более, чем на 1 трлн р. (до 9,01 трлн р.). Благодаря уже накопленным ресурсам, банки России не будут испытывать в 2016 г. проблем с капиталом. Рост капитала был вдвое выше прироста активов. Это стало следствием докапитализации через механизм облигаций федерального займа (т. е. когда банки получили от Агентства по страхованию вкладов более 800 млрд р., что обеспечило $80 \%$ роста собственного капитала банковской системы), а также относительно высокой прибыльности у ряда крупных банков (Сбербанка, Альфа-банка и банков с иностранным участием). По оценке экспертов, собственный капитал банков вырастет на 4-7 \% по итогам 2016 г., а средний норматив достаточности капитала снизится на 1,3-1,8 процентных пунктов ${ }^{6}$.

Рост капитала и прибыли дают возможность наращивать кредитование.

Общие объемы кредитных вложений российских банков в 2015 г. выросли более, чем на 7 трлн р. Однако темпы роста кредитования существенно замедлились (в 2-3 раза). Кредитный портфель отечественных банков показывает отрицательную динамику [7, с. 3]. Прирост кредитования физических лиц и вовсе составил отрицательную величину $(-5,7 \%)$. Заметно также снизилось качество кредитных портфелей российских коммерческих банков. Рост просроченной задолженности по данным РИА «Рейтинг» составил с 3,8 до 5,5 \%. Снижение качества кредитного портфеля объясняется во многом снижением темпов роста кредитования при относительно умеренном снижении платежной дисциплины заемщиков ${ }^{7}$

Ведущие экономисты страны настоятельно рекомендуют обновить банковские модели деятельности, констатируя тот факт, что ведущее место в этой работе должно занять повышение качества управления банковскими рисками и развитие правового и нормативного обеспечения их нейтрализации [8, с. 140]. Среди мер, направленных на регулирование рисков и повышение устойчивости банковского сектора, называют увеличение размера капитала банков, улучшение его качества и обеспечение достаточного уровня покрытия капиталом принимаемых кредитными организациями рисков; совершенствование банковского регулирования и банковского надзора, направленного на повышение качества банковского капитала и активов, увеличение транспарентности кредитных организаций, рост доверия к российским рейтинговым агентствам, необходимость реального учета этических принципов в практике функционирования отечественной банковской системы [9-12].

${ }^{6}$ URL : http://ria.ru/economy/20160218/1376642714.html\#ixzz41vrPiWl7.

${ }^{7}$ URL : http://riarating.ru/banks_study/20151225/630005336.html.

\section{Baikal Research Journal}

электронный научный журнал Байкальского государственного университета 
В настоящее время российский финансовый рынок занимает 95-е место из 140 возможных. В сложившейся ситуации ЦБ РФ предлагает до 2018 г. развивать финансовый рынок России по следующим десяти направлениям:

- рост финансовой грамотности населения;

- повышение доступности финансовых услуг для населения и малого и среднего бизнеса;

- рост доверия к банковской системе: пресечение появления недобросовестных участников и практик на финансовом рынке;

- расширение долевого финансирования инвесторами публичных компаний - эта задача ставится и ЦБ РФ, и Правительством РФ с 1991 г. с минимальными успехами;

- развитие рынка облигаций и синдицированного кредитования;

- повышение уровня квалификации работников на финансовом рынке;

- развитие макропруденциального надзора и оценки стабильности финансовых групп;

- цифровизация финансового рынка (применение новых технологий электронного взаимодействия на финансовом рынке);

- разработка и внедрение признанных международных стандартов;

- обеспечение финансовой стабильности ${ }^{8}$.

В 2015-2016 гг. центральной идеей стратегии ЦБ РФ в силу закрытия внешнего финансового рынка стали развитие внутреннего рынка облигаций и переориентация по крайней мере части корпоративных заемщиков с банковских кредитов на fixed assets (основные фонды) [13]. Э. Набиуллина и ранее констатировала эту необходимость, теперь подкрепленную санкционным режимом и потерей Российской Федерацией инвестиционного рейтинга.

В целом, несмотря на все непростые процессы, проистекающие в банковской системе Российской Федерации в настоящее время, ее деятельность характеризуется непрерывностью развития, равновесием в динамике основных направлений ее деятельности, которые считаются признаками устойчивости в работе системы. Следовательно, ее работу можно характеризовать как стабильную и уверенную, нацеленную на рост показателей ее развития и преодоление вызовов, брошенных ей временем.

В настоящее время особая роль национальной банковской системы состоит в обеспечении стабильного экономического роста, в расширении возможностей предприятий по привлечению финансовых ресурсов, в сохранении и приумножении сбережений граждан. Для активного участия банковского сектора России в модернизации экономики, а также для расширения инвестиционного кредитования необходим значительный финансовый капитал, именно поэтому капитализация российских банков является стратегическим направлением развития отечественного банковского сектора.

\section{Список использованной литературы}

1. Аксаков А. Банковская система прошла нижние значения в своем развитии [Электронный pecypc] / А. Аксаков. - Режим доступа: http://chuvashia.spravedlivo.ru/00-5134573.html.

2. Симановский А. Ю. Центробанк намерен удалить с российского рынка всех финансовых вампиров / А. Ю. Симановский // Российская газета. - 2015. - 8 июля.

3. Осколкова Н. А. Система страхования вкладов как гарантия стабильности осуществления банковской деятельности / Н. А. Осколкова // Финансы и кредит. - 2016. № 10 (682). - С. 23-32.

${ }^{8}$ Основные направления развития и обеспечения стабильности функционирования финансо-вого рынка Российской Федерации на период 2016-2018 годов. URL : http://www.cbr.ru/finmarkets/files/ development/opr_1618.pdf.

\section{Baikal Research Journal}

электронный научный журнал Байкальского государственного университета 
4. Оношко О. Ю. Тенденции развития банковской системы Российской Федерации / О. Ю. Оношко, А. П. Кряжева, И. Д. Шигаева // Актуальные тенденции развития мировой экономики : материалы Междунар. науч.-практ. конф. Иркутск, 15-16 марта 2016 г. / под ред. А. П. Суходолова, ЖЖ.-П. Гишара. - Иркутск : Изд-во Байкал. гос. ун-та, 2016. - 286 с.

5. Банковская система в современной экономике : учеб. пособие / под ред. О. И. Лаврушина. - М. : КноРус, 2011. - 360 с.

6. Яковлева К. О. Система страхования вкладов и ее роль в развитии ресурсной базы коммерческих банков / К. О. Яковлева // Теория и практика современной науки. - 2016. № 1 (7). - С. 405-408.

7. Фролова Е. Е. Тенденции и направления развития кредитного рынка (на примере Иркутской области) : монография / Е. Е. Фролова, Е. В. Кармадонова. - М. : Наука, 2013. $24 \mathrm{c}$.

8. Новые модели банковской деятельности в современной экономике : монография / под ред. О. И. Лаврушина. - М. : КноРус, 2015. - 168 с.

9. Коротаева Н. В. Тенденции развития банковской системы в посткризисный период / Н. В. Коротаева, М. В. Болдырева // Актуальные инновационные исследования: наука и практика. - 2010. - № 2. - С. 14.

10. Коротаева Н. В. Современная банковская система России: институциональный аспект / Н. В. Коротаева / Саяпинские чтения : материалы круглого стола. Тамбов, 28 марта 2014 г. / под ред. А. А. Бурмистрова. - Тамбов : Изд-во Тамбов. гос. ун-та, 2014. - С. 59-65.

11. Развитие банковской системы России в современных условиях / Н. В. Коротаева, Я. Ю. Радюкова, Н. Н. Пахомов, В. А. Савинков // Наука в современном информационном обществе : материалы VII Междунар. науч.-практ. конф. North Charleston, USA, 9-10 нояб. 2015 г. - CreateSpace, 2015. - T. 2. - C. 236-241.

12. Коротаева Н. В. Тенденции развития банковской системы в современных условиях / Н. В. Коротаева, Т. В. Борисова // Социально-экономические явления и процессы. — 2014. № $3(61)$. - C. 51-56.

13. Сотникова Л. Н. Банковская система РФ: состояние и перспективы развития / Л. Н. Сотникова, М. В. Ткачева // Вестник Воронежского государственного университета инженерных технологий. — 2015. — № 2 (64). — С. 260-266.

\section{References}

1. Aksakov A. Bankovskaya sistema proshla nizhnie znacheniya $v$ svoem razvitii [The banking system has passed the lower values in its development]. Available at: http://chuvashia.spravedlivo.ru/00-5134573.html. (In Russian).

2. Simanovsky A. Yu. Central Bank intends for removing all financial vampires from the Russian market. Rossiiskaya Gazeta, 2015, July 8. (In Russian).

3. Oskolkova N. A. Deposit insurance system as a stability guarantee for implementing banking performance. Finansy $i$ kredit $=$ Finance and Credit, 2016, no. 10 (682), pp. 23-32. (In Russian).

4. Onoshko O. Yu., Kryazheva A. P., Shigaeva I. D. Development trends of the Russian Federation banking system. In Sukhodolov A. P., Gishar Zh.-P. (eds). Aktual'nye tendentsii razvitiya mirovoi ekonomiki. Materialy Mezhdunarodnoi nauchno-prakticheskoi konferentsii. Irkutsk, 15-16 marta 2016 g. [Top Development Rents of the Global Economy. Proceedings of the International Research Conference. Irkutsk, March 15-16, 2016]. Irkutsk, Baikal State University Publ., 2016. 286 p. (In Russian).

5. Lavrushin O. I. (ed.). Bankovskaya sistema $v$ sovremennoi ekonomike [Banking system in modern economic paradigm]. Moscow, KnoRus Publ., 2011. 360 p.

6. Yakovleva K. O. Insurance system of bank deposits and its role in developing the resource base of commercial banks. Teoriya i praktika sovremennoi nauki= Theory and Practice of modern Science, 2016, no. 1 (7), pp. 405-408. (In Russian).

7. Frolova E. E., Karmadonova E. V. Tendentsii i napravleniya razvitiya kreditnogo rynka ( n a primere Irkutskoi oblasti) [Trends and directions of the credit market development (using the example of Irkutsk Oblast), Moscow, Nauka Publ., 2013. 24 p.

8. Lavrushin O. I. (ed.). Novye modeli bankovskoi deyatel'nosti v sovremennoi ekonomike [New models of banking performance in modern economic paradigm]. Moscow, KnoRus Publ., 2015. $168 \mathrm{p}$.

\section{Baikal Research Journal}

электронный научный журнал Байкальского государственного университета 
9. Korotayeva N. V., Boldyreva M. V. Tendencies of banking system development during the post-crisis period. Aktual'nye innovatsionnye issledovaniya: nauka i praktika = Topical Innovation Issues: Research \& Implementation, 2010, no. 2, pp. 14. (In Russian).

10. Korotayeva N. V. Russia's Modern banking system: an institutional aspect. In Burmistrova A. A. (ed.). Sayapinskie chteniya. Materialy kruglogo stola. Tambov. 28 marta 2014 g. [Readings from Sayapin. Materials of Round Table. Tambov, March 28, 2014]. Tambov State University Publ., 2014, pp. 59-65. (In Russian).

11. Korotayeva N. V., Radyukova Ya. Yu., Pakhomov N. N., Savinkov V. A. Development of Russia's banking system in the current environment. Nauka $v$ sovremennom informatsionnom obshchestve. Materialy VII Mezhdunarodnoi nauchno-prakticheskoi konferentsii [Science in modern information society. Materials of the 7 th International Research Conference]. CreateSpace, 2015, vol. 2, pp. 236-241. (In Russian).

12. Korotayeva N. V., Borisova T. V. Tendencies of development of Russia's banking system in present-day environment. Sotsial'no-ekonomicheskie yavleniya $i$ protsessy = Social and Economic Phenomena and Processes, 2014, no. 3 (61), pp. 51-56. (In Russian).

13. Sotnikova L. N., Tkacheva M. V. RF banking system: state and development prospects. Vestnik Voronezhskogo gosudarstvennogo universiteta inzhenernykh tekhnologii $($ VGUIT $)=H e r-$ ald of the Voronezh State University of Engineering Technology, 2015, no. 2 (64), pp. 260-266. (In Russian).

\section{Информация об авторах}

Оношко Ольга Юрьевна - кандидат экономических наук, доцент, кафедра банковского дела и ценных бумаг, Байкальский государственный университет, 664003, г. Иркутск, ул. Ленина, 11, e-mail: olga_onoshko@mail.ru.

Кряжева Алена Павловна - кандидат экономических наук, доцент, кафедра банковского дела и ценных бумаг, Байкальский государственный университет, 664003, г. Иркутск, ул. Ленина, 11, e-mail: kryazheva.alena68@mail.ru.

Шигаева Ирина Длитриевна - аспирант, кафедра банковского дела и ценных бумаг, Байкальский государственный университет, 664003, г. Иркутск, ул. Ленина, 11, e-mail: kumukva@rambler.ru.

\section{Authors}

Olga Yu. Onoshko - PhD in Economics, Associate Professor, Chair of Banking and Securities, Baikal State University, 11 Lenin St., 664003, Irkutsk, Russian Federation; e-mail: olga onoshko@mail.ru.

Alyona P. Kryazheva - PhD in Economics, Associate Professor, Chair of Banking and Securities, Baikal State University, 11 Lenin St., 664003, Irkutsk, Russian Federation; e-mail: kryazheva.alena68@mail.ru.

Irina D. Shigayeva - PhD Student, Chair of Banking and Securities, Baikal State University, 11 Lenin St., 664003, Irkutsk, Russian Federation; e-mail: kumukva@rumbler.ru.

\section{Библиографическое описание статьи}

Оношко О. Ю. Банковская система российской федерации: современное состояние и перспективы развития / О. Ю. Оношко, А. П. Кряжева, И. Д. Шигаева // Baikal Research Journal. — 2016. — T. 7, № 5. — DOI : 10.17150/2411-6262.2016.7(5).3.

\section{Reference to article}

Onoshko O. Yu., Kryazheva A. P., Shigayeva L. D. Banking system of the Russian Federation: current situation and development prospects. Baikal Research Journal, 2016, vol. 7, no. 5. DOI : 10.17150/2411-6262.2016.7(5).3. (In Russian).

\section{Baikal Research Journal}

